\title{
Co-evolution of port business ecosystem based on evolutionary game theory
}

\author{
Wenjuan $\mathrm{Li}^{i^{*}} \mathbb{D}^{\text {, }}$, Thierry Vanelslander ${ }^{2}$, Wei Liu ${ }^{1}$ and $\mathrm{Xu} \mathrm{Xu}^{3}$
}

\author{
* Correspondence: wjli@shmtu.edu. \\ cn \\ ${ }^{1}$ Shanghai Maritime University, \\ NO.1550 Haigang Ave, Shanghai \\ 201306, China \\ Full list of author information is \\ available at the end of the article
}

\begin{abstract}
As distributing centres of trade and transportation network, ports play an important role in the development of the national economy. With the changing of the global business environment, the port enterprise operation environment is continuously changing, and growing problems are becoming increasingly complex. Since challenges, uncertainties, risks, and crisis exist side by side, it is indispensable and beneficial to do a systematic analysis of the development of port enterprises from the perspective of biological co-evolution. This paper uses the evolutionary game model to discuss the dynamic change process and evolutionary stable strategy of the collaborative development of the core enterprise and cooperative enterprise in the port business ecosystem. Then, the influencing factors of enterprise decisionmaking or action selection are analysed, and the numerical model verifies the accuracy of the model. Finally, suggestions on the development of the port business ecosystem are put forward.
\end{abstract}

Keywords: Port business ecosystem, Core enterprise, Cooperative enterprise, Evolutionary game

\section{Introduction}

Ports are critical nodes of international trade. More than 90\% of world trade is realised through ports. However, with regional-economic integration and economic globalisation, many ports have common economic hinterlands, especially large and mediumsized ports. They usually compete fiercely in order to fight for limited resources or markets. As the global business environment changes, no company operates in isolation. Each exists in ecosystems. With the changes of the times, and the increasing complexity of the international environment, the traditional strategies and theory cannot meet the requirements of sustainable port development any more. The competition among the port enterprises is not only the competition of the core competence of the port, the port industry chain or the port supply chain, but also the competition of the port business ecosystem.

The collaboration of the port business ecosystem includes horizontal collaboration, vertical collaboration, and collaboration between enterprises and the environment. Horizontal collaboration in the port business ecosystem mainly refers to the cooperation between the port enterprise, which is at the core of the ecosystem, and other port

(c) The Author(s). 2020 Open Access This article is licensed under a Creative Commons Attribution 4.0 International License, which permits use, sharing, adaptation, distribution and reproduction in any medium or format, as long as you give appropriate credit to the original author(s) and the source, provide a link to the Creative Commons licence, and indicate if changes were made. The images or other third party material in this article are included in the article's Creative Commons licence, unless indicated otherwise in a credit line to the material. If material is not included in the article's Creative Commons licence and your intended use is not permitted by statutory regulation or exceeds the permitted use, you will need to obtain permission directly from the copyright holder. To view a copy of this licence, visit http://creativecommons.org/licenses/by/4.0/. 
enterprises to achieve horizontal collaboration of interests by complementing resources and preventing vicious competition. The vertical collaboration in the port business ecosystem mainly refers to the vertical benefit collaboration formed by the core enterprise with upstream and downstream enterprises in intensive operation and risk-sharing.

In the port business ecosystem, there are mainly two types of enterprises, namely the core enterprise and the associated cooperative enterprise. The core enterprise in the port business ecosystem is the port enterprise. Port enterprises are market-oriented economic organisations, engaged in port production and operation activities with profit as the primary purpose (Yang 2009). Port enterprises include state-owned port enterprises, joint venture port enterprises and private port enterprises. The port enterprise is a terminal operating company. It can be an individual port enterprise or a port enterprise group. Cooperative enterprises include other port enterprises, shipping companies and other port logistics service providers, including warehousing enterprises and logistics enterprises.

The core enterprise and the cooperative enterprises play games in the process of collaborative development, and the enterprises and government departments also play games. This paper only discusses the games between the core enterprise and cooperative enterprise. For the feasibility of the operation, this model analyses the problem abstract as the game between the core enterprise and the individual cooperative enterprise.

Section 2 assesses the literature concerning business ecosystems, port settings and approaches to assess the evolution that the port business ecosystem has gone through. That is the basis for the model that is set up in section 3. Section 4 shows the results of applying the model. Section 5 derives recommendations for policy and practice. Section 5 finally gives the conclusions.

\section{Literature review}

In a complex and volatile business environment, it is blind to care only about the business development of one's own business. Therefore, the port enterprises need to pay close attention to the changes occurring in other port enterprises, port service suppliers, port service customers (shipping companies, land transport companies, shippers and so on), port industry, political environment, macro-economic environment, social environment, and natural environment of port business. Moreover, port enterprises also need to make the appropriate adjustments according to these changes, to improve the adaptability to external markets.

Moore (1993), a famous American strategic management scientist, puts forward the concept of 'business ecosystem'. He explains the new competition among enterprises, the symbiosis and the way of sustainable development of enterprises and environment. Moore (1996) points out that the business ecosystem was an economic community based on the interaction between the organisation and the individual. He even suggested that the term 'business ecosystem' should replace the term 'industry'.

Iansiti and Levien (2004) employ the analogy of natural ecosystems to describe the inner workings of the business ecosystem. They identify the four roles that firms play within the business ecosystem, which were keystones, landlords, dominators and niche players. They explain that the development of each enterprise in the business ecosystem is closely related to the development of the whole business ecosystem. Peltoniemi and Vuori (2004) present the focal complexity aspects appearing in business ecosystems 
which are self-organisation, emergence, co-evolution and adaptation. Ketchen et al. (2014) imply that traditional supply chains appear to be giving way to supply ecosystems. Supply ecosystems represent a set of interdependent and coordinated organisations that share common adaptive challenges and that collectively shape the creation and nurturing of a sourcing base that contribute to competitive advantage and superior performance.

The business ecosystem is an economic community which is supported by a foundation of interacting organisations and individuals. The economic community produces goods and services of value to customers, who are themselves members of the ecosystem. The member organisms also include suppliers, lead producers, competitors, and other stakeholders. Over time, they coevolve their capabilities and roles and tend to align themselves with the directions set by one or more central companies (Moore 1996). It means that companies need to become proactive in developing mutually beneficial relationships with customers, suppliers, and even competitors. Business ecosystems are larger, more diverse, and more fluid than a traditional set of bilateral partnerships or complementors. By leveraging ecosystems, companies can deliver sophisticated solutions while maintaining corporate focus (Williamson and de Meyer 2012). Moreover, the concept of the business ecosystem equips companies with a more comprehensive view of cross-industry collaboration, rather than directly linking partners in the supply chain, as viewed through a traditional lens, which is conducive to reducing the risk of market demand uncertainty brought by the development of emerging industries (Rong et al. 2013).

This strategic management concept is relevant for ports because ports can be considered business networks in an analogy with the business ecosystem (Pettit and Beresford 2017). Ports are confronted with a closer integration in the maritime and shipping industries. The cooperation agreements taking place in the maritime and shipping industries can take several forms, such as alliances and mergers among shipping lines, conferences, the involvement of shipping companies in terminal management, and extending interests in inland transport of shipping companies (Van de Voorde and Vanelslander 2014).

\section{Port clusters vs. port business ecosystems}

Ports are defined in different ways, quite often as clusters or networks of various interrelated companies. A port cluster is the set of interdependent firms engaged in portrelated activities, located within the same port region and possibly with similar strategies leading to competitive advantage and characterised by a joint competitive position vis-á-vis the environment external to the cluster (Kocsis 2011). On the other hand, the port business ecosystem (PBE hereafter) is a sort of economic association that is formed by ports and related organisations. Members of the PBE include port enterprises, shipping companies, freight forwarding companies, shippers, market intermediaries. Material, energy and information flows travel through the value network among members of the PBE. The members of the PBE make rational use of resources and improve the work efficiency and the ability to work together so that the $\mathrm{PBE}$ is in a relatively stable dynamic equilibrium in a certain period and provides quality services to customers (Li et al. 2017). 
The port cluster has regional characteristics, which is to form scale effects and external effects through the clustering of port industry regions, to improve the competitiveness of regional ports (de Langen and Haezendonck 2012). Unlike a port cluster, the $\mathrm{PBE}$ is not limited by region, and its goal is the sustainable development of the ecosystem. Moreover, in a port cluster, enterprises mainly play parallel roles horizontally, while in a port business ecosystem, enterprises not only play a part in the system horizontally with enterprises in similar industries but also play a link in the value chain vertically.

However, both the PBE and port cluster are economic communities, and both induce competition and cooperation (Kocsis 2011). The port cluster emphasises more competition than the PBE, while the PBE emphasises more cooperation and co-evolution than the port cluster (Peltoniemi and Vuori 2004). Moreover, the relationship among enterprises in the PBE is more close and involved than in the port cluster. When a company enters the PBE from the port cluster, it means that the company is shifting away from focusing on its development to focusing on the combination of its development, and the operation of the whole system. Research on ports from the perspective of the PBE is more necessary for the development of modern port enterprises.

Most research based on the port industry focuses on the competitive strategies of port enterprises, the establishment of port cooperation alliances or port clusters. However, there is little research on the PBE, let alone involving the dynamic evolution of the PBE. In fact, in the process of collaborative development, enterprises in the PBE will learn from each other and adjust their business strategies.

\section{Review of the methodologies employed in port studies}

Slack (1985) discusses that the shippers employ in the port selection process are influenced more by price and service considerations of land and ocean carriers than by differences in the port infrastructures. Wang and Meng (2004) establish the evolutionary game model of supply chain partnership based on the view of evolutionary game theory and analysed its dynamic evolutionary procedure. De Langen and Visser (2005) analyse the competitiveness of the Lower Mississippi seaport from a cluster perspective, discuss the importance of local governance and collective action regimes for the competitiveness of the cluster. Mangan et al. (2008) show that ports could play a variety of different roles within supply chains, and they are not restricted to their traditional role of simple transhipment point for freight. Zhou (2011) establishes the decision-making model in which port enterprises deal with emergencies through ability cooperation. Zhao (2012) summarises the concept of port strategic synergy, systematically study the horizontal strategic coordination and vertical strategic coordination, and then put forward the strategic integration of alliance of ports in Zhejiang province in China. McLaughlin and Fearon (2013) consider strategic port cooperation through a new conceptual cooperation/competition matrix, which can be used to evaluate the response strategies of ports to inter-port rivalry and changing competitive maritime dynamics.

Shao (2013) employs theoretical methods and tools such as game theory, contract theory, system modelling, simulation, and ANP to research coordination mechanism of port service supply chain. Wang and Zhang (2013) put forward the meaning of shipping cluster ecosystem, and analyse the endogenous mechanism of shipping cluster 
ecosystem from three aspects: the agglomeration and differentiation of individual enterprises, the competition and cooperation of industrial groups, and the co-evolution of shipping cluster and external environment. Hidalgo-Gallego et al. (2017) provide a review of recent research in the port industry, use strategic interaction approaches from an industrial organisation, game theory and concentrate on five topics: ownership, the relationship between ports and their hinterlands, port authorities and port operators' relations, capacity investment decisions, and port specialisation. Kotowska (2017) argues that the competitiveness of seaports is a complex issue. It may be viewed from the level of the whole region, the port itself as well as an individual port enterprise. Finally, Zhang and Liu (2017) analyse the competitive advantages of port enterprise in China and makes a corresponding discussion on the future strategic choices of port enterprises.

The traditional theory of games imposes a very high rationality requirement upon agents. Evolutionary game theory no longer models human beings as super-rational players but thinks that human beings usually achieve game equilibrium by trial and error, which is more realistic in theory. In the process of collaborative development, enterprises in the PBE will adjust their business strategies. The evolution of enterprises is dynamic. The traditional theory of games lacks an explicit treatment of the dynamics of rational deliberation.

This paper uses evolutionary game theory to analyse the co-evolution of the PBE. The evolutionary game theory was first developed by Fisher (1930) in his attempt to explain the approximate equality of the sex ratio in mammals. At the heart of the evolutionary game theory lie the concepts of evolutionary stability strategy and replicator dynamics. Within the scope of the paper, the concept of evolutionary stable strategy is presented as defined by Smith (1972). Evolutionary stable strategy (hereafter ESS) refers to the strategy adopted by most members of a population, and the benefits of the ESS are superior to those of other strategies.

On the other hand, replicator dynamics, offered by Taylor and Jonker (1978) provide continuous dynamics for evolutionary game theory. Therefore, ESS represents the stable state of evolutionary game, and the replicator dynamics represents the process of dynamic convergence to the stable state. The replicator dynamic equations of core enterprises and cooperative enterprises in the PBE are constructed, and ESSs are analysed. Then the factors affecting enterprises' ESSs will be found out.

The literature has laid a foundation for the research in this paper. The model to assess this is developed in the next section.

\section{Construction of the evolutionary game model}

This section consecutively addresses the assumptions made for the evolutionary game model and its actual construction.

\section{Assumptions and parameter setting of evolutionary game model}

Based on evolutionary game theory and the previous analysis, the following assumptions are made: 1 ) the players in the game follow bounded rationality and need to play multiple times; and 2) information asymmetry exists in the core enterprise and the cooperative enterprise, and they aim to maximise their interests. 
Referring to the related literature (Wang and Meng 2004; Zhou and Ji 2008; Wang and Zhang 2014; Li et al. 2015), the relevant parameters are set as presented in the next paragraphs.

In the case of collaboration, the core enterprise and cooperative enterprise cooperate according to the established contractual arrangements and need to input the cooperation cost and carry out revenue distribution.

When they both adopt the strategy of collaboration, $\Delta \pi$ is the sum of the excess returns each side gets from a collaboration strategy. For example, port enterprise A is the core enterprise, and port enterprise $B$ is the cooperative enterprise. They cooperate per the contract. If port enterprise A and port enterprise B cooperate, and they share information about shippers, the ecosystem will get an excess return. $\alpha$ is the distribution coefficient between the core enterprise and the cooperative enterprise, and $0 \leq \alpha \leq 1$. When adopting a collaboration strategy, the core enterprise and cooperative enterprise should pay information cost, communication cost and other costs for collaboration. $\theta_{1}$ and $\theta_{2}$ represent the increased cost of the core enterprise and cooperative enterprise, respectively, for collaboration. $\pi_{1}$ and $\pi_{2}$ represent the revenue of the core enterprise and cooperative enterprise, respectively, when they are in the case of non-collaboration.

$\Delta E_{1}$ and $\Delta E_{2}$ respectively represent the increase in the total revenue brought to the system by the unilateral collaboration of the core enterprise and the cooperative enterprise. If one player cooperates and the other adopts opportunism and does not cooperate, the non-coordinator will free ride, and get the extra benefit because of the cooperating party. For example, if port enterprise A shares shippers' information with enterprise B, while enterprise $B$ does not share shippers' information with enterprise $A$, then enterprise $B$ will gain additional benefits from the information shared by enterprise A.

In order to ensure the effective promotion of future cooperation, the distribution coefficient between the core enterprise and the cooperative enterprise remains $\alpha$.

When the core enterprise cooperates, and the cooperative enterprise does not, the increased benefit of the core enterprise and the cooperative enterprise is $\alpha \Delta \mathrm{E}_{1}$ and $(1-\alpha) \Delta \mathrm{E}_{1}$ respectively. When the cooperative enterprise cooperates, and the core enterprise does not, the increased benefit of the core enterprise and the cooperative enterprise is $\alpha \Delta \mathrm{E}_{2}$ and (1 $-\alpha) \Delta \mathrm{E}_{2}$, respectively. Because the ecosystem has synergistic effects, then $\Delta \pi>\Delta \mathrm{E}_{1}+\Delta \mathrm{E}_{2}$.

At the same time, to reduce the possibility of either party adopting a non-cooperative strategy, the non-collaboration side needs to pay the penalty to the other side as compensation. The penalty is expressed in terms of $P$. So in the same case, if port enterprise A shares shippers' information with enterprise B, but enterprise B takes the strategy of non-collaboration, and does not share shippers' information with enterprise A, then enterprise $\mathrm{B}$ need to pay $P$ to enterprise $\mathrm{A}$.

In the $\mathrm{PBE}$, when the port enterprise and the cooperative enterprise start to enter into the state of cooperation, they can choose to continue to collaborate, or they can choose not to collaborate, which means that their behaviour strategy set is \{collaboration, non-collaboration\}. In the development process of the PBE, the probability that a core enterprise chooses a 'collaboration' strategy is $x$, then the probability of 'non-collaboration' is $(1-x), 0 \leq x \leq 1$. If the probability of a cooperative enterprise choosing a collaboration strategy is $y$, then the probability of 'non-collaboration' is $(1-y), 0 \leq y \leq 1$.

According to the above, the payoff matrix of the core enterprise and cooperative enterprise is built, as shown in Table 1. 
Table 1 Payoff Matrix

\begin{tabular}{lll}
\hline The Core enterprise & The cooperative enterprise & \\
\cline { 2 - 3 } & Collaboration $\boldsymbol{y}$ & Non-collaboration(1-y) \\
\hline Collaboration $x$ & $\pi_{1}+a \Delta \pi-\theta_{1}$ & $\pi_{1}+a \Delta E_{1}-\theta_{1}+P$ \\
& $\pi_{2}+(1-a) \Delta \pi-\theta_{2}$ & $\pi_{2}+(1-a) \Delta E_{1}-P$ \\
Non-collaboration $(1-x)$ & $\pi_{1}+a \Delta E_{2}-P$ & $\pi_{1}$ \\
& $\pi_{2}+(1-a) \Delta E_{2}+P-\theta_{2}$ & $\pi_{2}$ \\
\hline
\end{tabular}

Source: Authors' computing

\section{Construction of evolutionary game model}

According to the game matrix of the port enterprise and cooperative enterprise, when the core enterprise adopts the strategy of collaboration, its expected revenue is:

$$
u_{x}=y \cdot\left(\pi_{1}+\alpha \Delta \pi-\theta_{1}\right)+(1-y) \cdot\left(\pi_{1}+\alpha \Delta E_{1}-\theta_{1}+P\right)
$$

When the core enterprise adopts the strategy of non-collaboration, its expected revenue is:

$$
u_{1-x}=y \cdot\left(\pi_{1}+\alpha \Delta E_{2}-P\right)+(1-y) \cdot \pi_{1}
$$

The average expected revenue of the core enterprise is:

$$
\bar{u}_{1}=x \cdot u_{x}+(1-x) \cdot u_{1-x}
$$

Therefore, according to evolutionary game theory, the replicator dynamics equation of the core enterprise in the PBE is:

$$
\frac{d x}{d t}=x\left(u_{x}-\bar{u}_{1}\right)=x \cdot(1-x) \cdot\left[\alpha y\left(\Delta \pi-\Delta E_{1}-\Delta E_{2}\right)-\left(\theta_{1}-P-\alpha \Delta E_{1}\right)\right]
$$

When the cooperative enterprise adopts the strategy of collaboration, its expected revenue is:

$$
u_{y}=x\left[\pi_{2}+(1-\alpha) \Delta \pi-\theta_{2}\right]+(1-x) \cdot\left[\pi_{2}+(1-\alpha) \Delta E_{2}+P-\theta_{2}\right]
$$

When the cooperative enterprise adopts the strategy of non-collaboration, its expected revenue is:

$$
u_{1-y}=x\left[\pi_{2}+(1-\alpha) \Delta E_{1}-P\right]+(1-x) \cdot \pi_{2}
$$

The average expected revenue of the cooperative enterprise is:

$$
\begin{aligned}
\bar{u}_{2}= & y \cdot u_{y}+(1-y) \cdot u_{1-y} \\
= & y\left\{x\left[\pi_{2}+(1-\alpha) \Delta \pi-\theta_{2}\right]+(1-x) \cdot\left[\pi_{2}+(1-\alpha) \Delta E_{2}+P-\theta_{2}\right]\right\}+(1-y) \\
& \times\left\{x\left[\pi_{2}+(1-\alpha) \Delta E_{1}-P\right]+(1-x) \cdot \pi_{2}\right\}
\end{aligned}
$$

Then, according to evolutionary game theory, the replicator dynamics equation of the cooperative enterprise in the PBE is:

$$
\frac{d y}{d t}=y\left(u_{y}-\bar{u}_{2}\right)=y(1-y)\left\{(1-\alpha) x\left(\Delta \pi-\Delta E_{1}-\Delta E_{2}\right)-\left[\theta_{2}-P-(1-\alpha) \Delta E_{2}\right]\right\}
$$

By setting $\frac{d x}{d t}=0, \frac{d y}{d t}=0$,it can be concluded that there are five equilibrium points of the game between the core enterprise and cooperative enterprise in the PBE, which are $\mathrm{O}(0, \quad 0), \mathrm{A}(1, \quad 0), \mathrm{B}(0,1), \mathrm{C}(1, \quad 1)$, and $\mathrm{D}\left(\frac{\theta_{2}-P-(1-\alpha) \Delta E_{2}}{(1-\alpha) \cdot\left(\Delta \pi-\Delta E_{1}-\Delta E_{2}\right)}, \quad \frac{\theta_{1}-P-\alpha \Delta E_{1}}{\alpha\left(\Delta \pi-\Delta E_{1}-\Delta E_{2}\right)}\right)$. 


\section{Results from applying the evolutionary game model}

This section first describes the results of applying the evolutionary game model, and the optimal situations obtained. Next, it tests for the impacts of specific parameters.

\section{The analysis of the ESS in the PBE}

This section consecutively addresses the ESS analysis from the point of the core enterprise, respectively, the cooperative enterprise.

The analysis of the ESS of the core Enterprise

The following situations are discussed:

(1) When $0<\frac{\theta_{1}-P-\alpha \Delta E_{1}}{\alpha\left(\Delta \pi-\Delta E_{1}-\Delta E_{2}\right)}<1$, that is when $0<\theta_{1}-P-\alpha \Delta E_{1}<\alpha\left(\Delta \pi-\Delta E_{1}-\Delta E_{2}\right)$, if $y>\frac{\theta_{1}-P-\alpha \Delta E_{1}}{\alpha\left(\Delta \pi-\Delta E_{1}-\Delta E_{2}\right)}$, then $F^{\prime}(0)>0, \quad F^{\prime}(1)<0$ (Fig. 1a). Thus, the ESS of the core enterprise is $x^{*}=1$. If $\mathrm{y}=y^{*}=\frac{\theta_{1}-P-\alpha \Delta E_{1}}{\alpha\left(\Delta \pi-\Delta E_{1}-\Delta E_{2}\right)}, \quad \frac{d x}{d t} \otimes 0$, the phase diagram of replicator dynamics (Fig. 1b) shows that all $x$ are in an evolutionary stable state. If $y<\frac{\theta_{1}-P-\alpha \Delta E_{1}}{\alpha\left(\Delta \pi-\Delta E_{1}-\Delta E_{2}\right)}$, then $F^{\prime}(0)<0, F^{\prime}(1)>0, \quad$ (Fig. 1c). Therefore, the ESS is $x^{\prime \prime}=0$.

(2) When $\frac{\theta_{1}-P-\alpha \Delta E_{1}}{\alpha\left(\Delta \pi-\Delta E_{1}-\Delta E_{2}\right)}>1$, that is when $\theta_{1}-P-\alpha \Delta E_{1}>\alpha\left(\Delta \pi-\Delta E_{1}-\Delta E_{2}\right)>$ 0 , then $F^{\prime}(0)<0, \quad F^{\prime}(1)>0$ (Fig. 2). The ESS is $x^{*}=0$.

(3) When $\frac{\theta_{1}-P-\alpha \Delta E_{1}}{\alpha\left(\Delta \pi-\Delta E_{1}-\Delta E_{2}\right)}<0$ (Fig. 3), $F^{\prime}(0)>0, F^{\prime}(1)<0$, the ESS is $x^{\prime \prime}=1$.

\section{The analysis of the ESS of the cooperative Enterprise}

The following situations are discussed:

(1) When $0<\frac{\theta_{2}-P-(1-\alpha) \Delta E_{2}}{(1-\alpha) \cdot\left(\Delta \pi-\Delta E_{1}-\Delta E_{2}\right)}<1$,if $x>\frac{\theta_{2}-P-(1-\alpha) \Delta E_{2}}{(1-\alpha) \cdot\left(\Delta \pi-\Delta E_{1}-\Delta E_{2}\right)}$, then $\mathrm{F}^{\prime}(0)>0, \mathrm{~F}^{\prime}(1)$ $<0$ (Fig. 4a). So the ESS is $y^{*}=1$. If $x=x^{*}=\frac{\theta_{2}-P-(1-\alpha) \Delta E_{2}}{(1-\alpha) \cdot\left(\Delta \pi-\Delta E_{1}-\Delta E_{2}\right)}, \frac{d y}{d t} \otimes 0$ (Fig. 4b), all $y$ is in an evolutionary stable state. If $x<\frac{\theta_{2}-P-(1-\alpha) \Delta E_{2}}{(1-\alpha) \cdot\left(\Delta \pi-\Delta E_{1}-\Delta E_{2}\right)}$, then $\mathrm{F}^{\prime}(0)<0, \mathrm{~F}^{\prime}$ (1) $>0$ (Fig. 4c). The ESS is $y^{*}=0$.

(2) When $\frac{\theta_{2}-P-(1-\alpha) \Delta E_{2}}{(1-\alpha) \cdot\left(\Delta \pi-\Delta E_{1}-\Delta E_{2}\right)}>1$, that is when $\theta_{2}-(1-\alpha) \Delta E_{2}>(1-\alpha) \cdot\left(\Delta \pi-\Delta E_{1}-\right.$ $\left.\Delta E_{2}\right)$ (Fig. 5), then $\mathrm{F}^{\prime}(0)<0, \mathrm{~F}^{\prime}(1)>0$. The ESS is $y^{*}=0$.

(3) When $\frac{\theta_{2}-P-(1-\alpha) \Delta E_{2}}{(1-\alpha) \cdot\left(\Delta \pi-\Delta E_{1}-\Delta E_{2}\right)}<0$ (Fig. 6),then $\mathrm{F}^{\prime}(0)>0, \mathrm{~F}^{\prime}(1)<0$. The ESS is $y^{*}=1$.

If Figs. 1 and 4 are placed on a coordinate plane, Fig. 7 is obtained. Out of the five local equilibrium points $\mathrm{O}, \mathrm{A}, \mathrm{B}, \mathrm{C}$ and $\mathrm{D}$, equilibrium points $\mathrm{O}(0,0)$ and $\mathrm{C}$

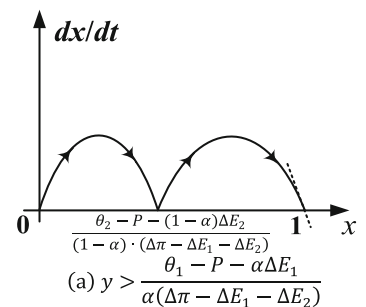



(b) $y=\frac{\theta_{1}-P-\alpha \Delta E_{1}}{\alpha\left(\Delta \pi-\Delta E_{1}-\Delta E_{2}\right)}$

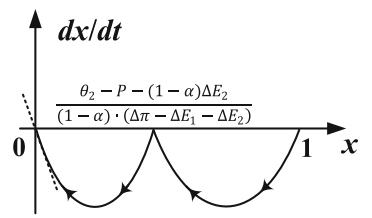

(c) $y<\frac{\theta_{1}-P-\alpha \Delta E_{1}}{\alpha\left(\Delta \pi-\Delta E_{1}-\Delta E_{2}\right)}$

Fig. 1 Phase diagram when $\mathbf{0}<\frac{\theta_{1}-P-a \Delta E_{1}}{\boldsymbol{a}\left(\Delta \pi-\Delta E_{1}-\Delta E_{2}\right)}<\mathbf{1}$ 


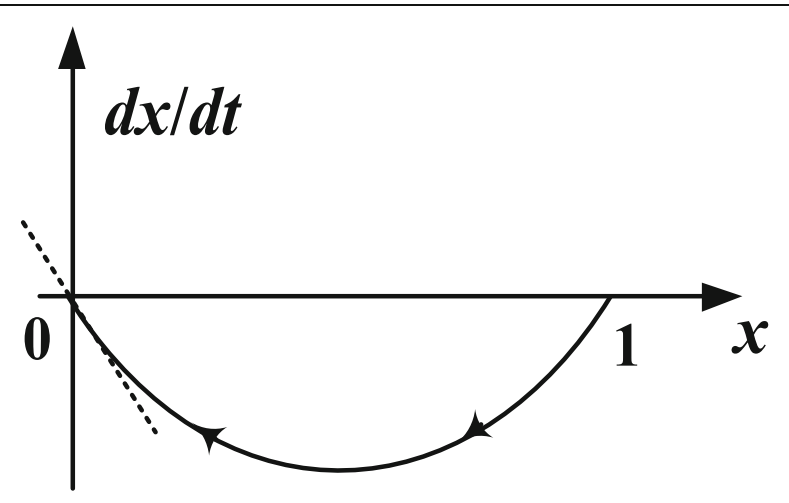

Fig. 2 Phase diagram when $\frac{\theta_{1}-P-a \Delta E_{1}}{a\left(\Delta \pi-\Delta E_{1}-\Delta E_{2}\right)}>1$,Source: Authors' processing

$(1,1)$ are stable. This means that when the system reaches stable equilibrium, both core enterprise and cooperative enterprise will choose collaboration strategy or non-collaboration strategy.

In summary, it can be seen that when the enterprises are with bounded rationality, the ESS of the core enterprise and the cooperative enterprise in the PBE is related to the initial strategy adopted by them, the benefit distribution coefficient, the cooperative cost, and the penalty. The impact of these elements is further detailed in the next section.

\section{Influencing factors of co-evolution of the PBE}

This section assesses the impact of the initial state, the benefit distribution, the cooperative cost and the penalty.

\section{Effect of initial state on the system evolution}

In case of the particularity of the same data, $\theta_{1} \neq \theta_{2}, \Delta E_{1} \neq \Delta E_{2}$ is taken.Furthermore, $\theta_{1}$ $=8, \theta_{2}=10, P=2, \Delta E_{1}=11, \Delta E_{2}=14, \Delta \pi=29, \alpha=0.5$ is set. When $0<$ $\frac{\theta_{1}-P-\alpha \Delta E_{1}}{\alpha\left(\Delta \pi-\Delta E_{1}-\Delta E_{2}\right)}<1$, also $0<\frac{\theta_{2}-P-(1-\alpha) \Delta E_{2}}{(1-\alpha) \cdot\left(\Delta \pi-\Delta E_{1}-\Delta E_{2}\right)}<1$, if the initial state is as follows:

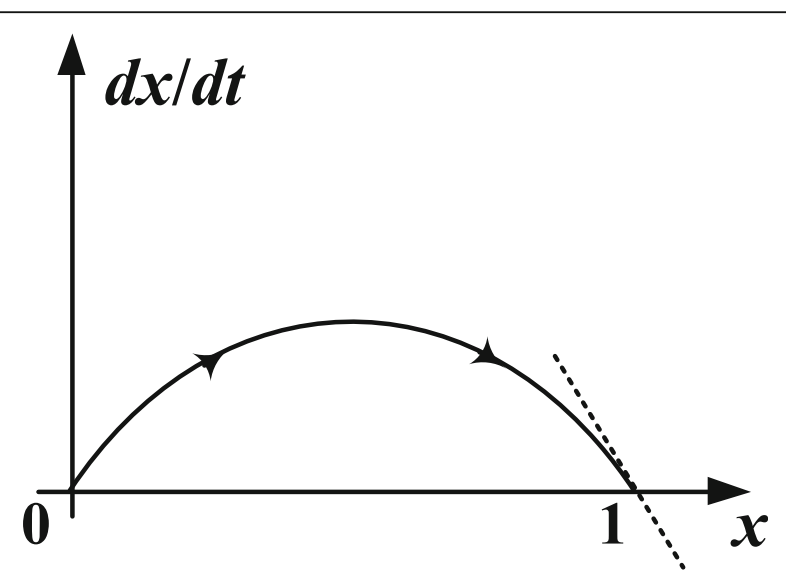

Fig. 3 Phase diagram when $\frac{\theta_{1}-\boldsymbol{P}-\boldsymbol{a} \Delta E_{1}}{\boldsymbol{a}\left(\Delta \pi-\Delta E_{1}-\Delta E_{2}\right)}<\mathbf{0}$,Source: Authors' processing 


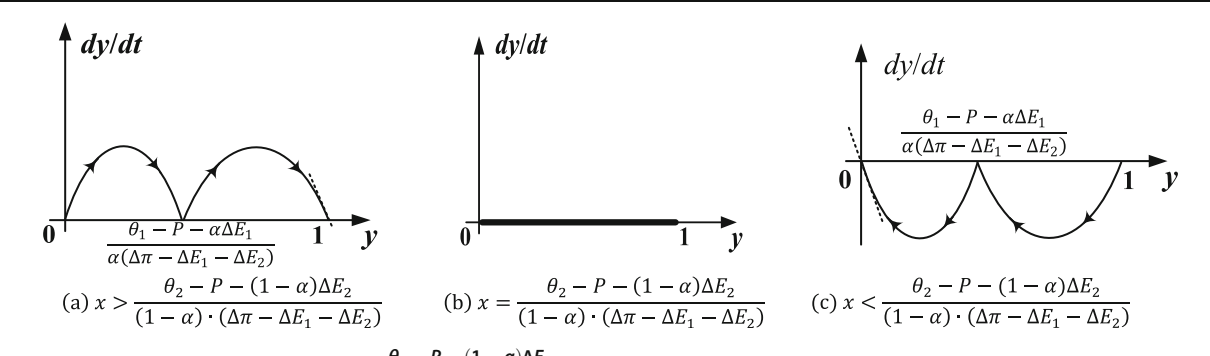

Fig. 4 Phase diagram when $0<\frac{\theta_{2}-P-(1-a) \Delta E_{2}}{(1-a) \cdot\left(\Delta \pi-\Delta E_{1}-\Delta E_{2}\right)}<1$. Source: Authors' processing

$(0.1,0.1),(0.2,0.2),(0.3,0.3),(0.4,0.4),(0.5,0.5,0.6,0.6)$. Figure 8 is obtained by using MATLAB 2016 to simulate the evolution game of the PBE. The horizontal axis (x) indicates the probability that the core enterprise adopts a collaboration strategy, and the vertical axis $(y)$ indicates the probability that the cooperative enterprise adopts a cooperative strategy.

As shown in Fig. 8, the larger the probability of the core enterprise choosing a collaboration strategy, the more the cooperative enterprise tends to choose a collaboration strategy. The smaller the probability of the core enterprise choosing a collaboration strategy, the more the cooperative enterprise tends to choose a noncollaboration strategy. When the initial values are $(0.1,0.1),(0.2,0.2),(0.3,0.3)$, the evolutionary stable equilibrium is $(0,0)$. When the initial states are $(0.4,0.4)$, $(0.5,0.5),(0.6,0.6)$, the evolutionary stable point is $(1,1)$. Even if other parameters are the same, because of the different initial states, the stability points of dynamic evolution will be different, which also verifies the contents of the ESS mentioned above.

\section{The influence of distribution coefficient on the system evolution}

Similar to the above numerical simulation, $\theta_{1}=8, \theta_{2}=10, P=2, \Delta E_{1}=11, \Delta E_{2}=14$, $\Delta \pi=29$ is taken. If the distribution coefficient $\alpha$ equals to $0.3,0.4,0.5,0.6,0.7$, initial values $x=0.5$ and $y=0.5$, Fig. 9 is obtained by using MATLAB 2016 to numerically simulate processes of the evolution game. The horizontal axis $(x)$ indicates the probability that the core enterprise adopts a collaboration strategy, and

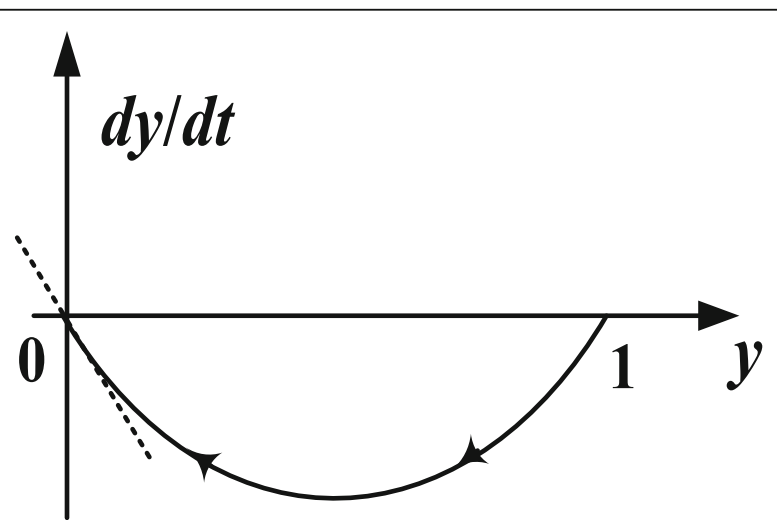

Fig. 5 Phase diagram when $\frac{\theta_{2}-P-(1-a) \Delta E_{2}}{(1-a) \cdot\left(\Delta \pi-\Delta E_{1}-\Delta E_{2}\right)}>1$, Source: Authors' processing 


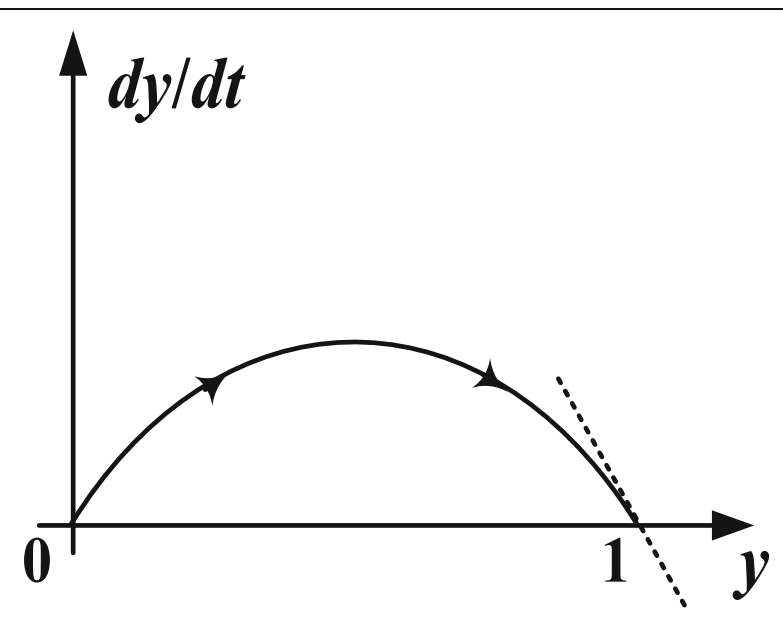

Fig. 6 Phase diagram when $\frac{\theta_{2}-P-(1-a) \Delta E_{2}}{(1-a) \cdot\left(\Delta \pi-\Delta E_{1}-\Delta E_{2}\right)}<\mathbf{0}$.Source: Authors' processing

the vertical axis $(y)$ indicates the probability that the cooperative enterprise adopts a collaboration strategy. When $\alpha=0.3,0.4$, the stable equilibrium point of system evolution is $(0,1)$. When $\alpha=0.5$, the stable equilibrium point of system evolution is $(1,1)$. When $\alpha=0.6,0.7$, the stable equilibrium point of system evolution is $(1,0)$.

As seen from Fig. 9, with the change of distribution coefficient, the evolutionary stability point of system evolution changes. The probability of the core enterprise adopting a collaboration strategy increases with the increase of $\alpha$, while the probability of the cooperative enterprise adopting a cooperative strategy decreases with the increase of $\alpha$. When $\alpha=0.7$, the cooperative enterprise has the lowest probability to adopt a collaboration strategy in the above initial values, and eventually stabilises to non-collaboration. In the situation of $\alpha=0.7$, the cooperative enterprise and the core enterprise have realised value creation. However, the ideal value sharing is not realised, so the cooperative enterprise adopts a noncooperative strategy.

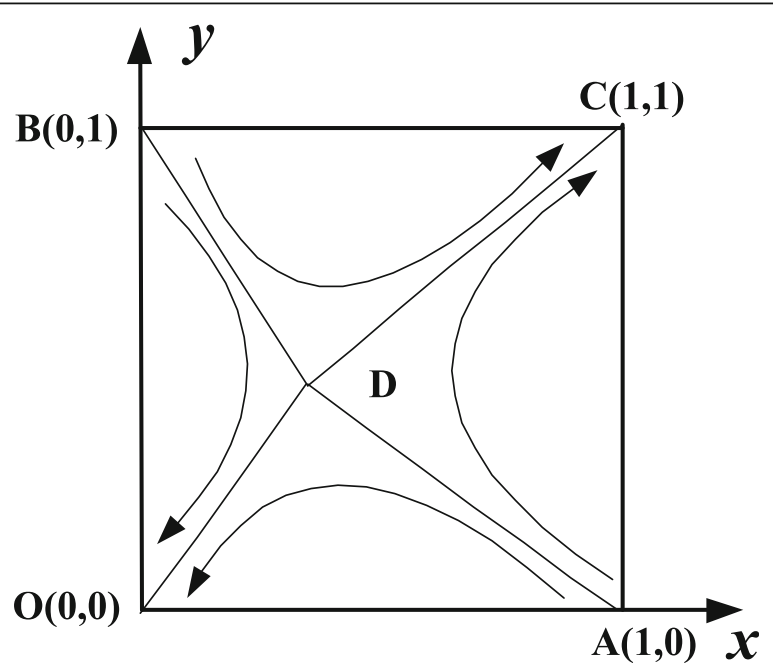

Fig. 7 The evolution phase diagram about core enterprises and cooperative enterprises. Source: Authors' processing 


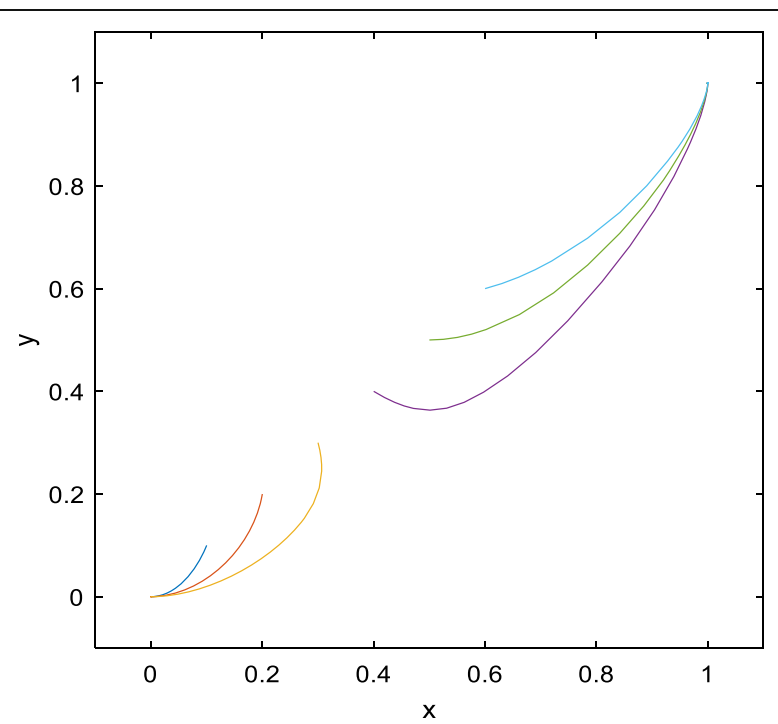

Fig. 8 Evolutionary game of the system with different initial values. Source: Authors' processing using Matlab

The impact of the collaborative cost on the system evolution

If $\theta_{1}=8, P=2, \Delta E_{1}=11, \Delta E_{2}=14, \Delta \pi=29, \alpha=0.5$ is set and the collaborative costs $\theta_{2}$ equals to $8,9,10,11,12$, Fig. 10 is obtained by using MATLAB 2016 to simulate processes of the evolutionary game of PBE. With the increase of collaborative cost, the stable strategy of system evolution changes from $(1,1)$ to $(0,0)$. If $\theta_{2}$ is kept unchanged and $\theta_{1}$ is changed for numerical simulation, a similar result can be obtained. Whether it is a core enterprise or a cooperative enterprise, the lower the cost of adopting a collaboration strategy, the more inclined it is to adopt a collaboration strategy. In contrast, the higher the cost, the more inclined it is to adopt the non-collaboration strategy.

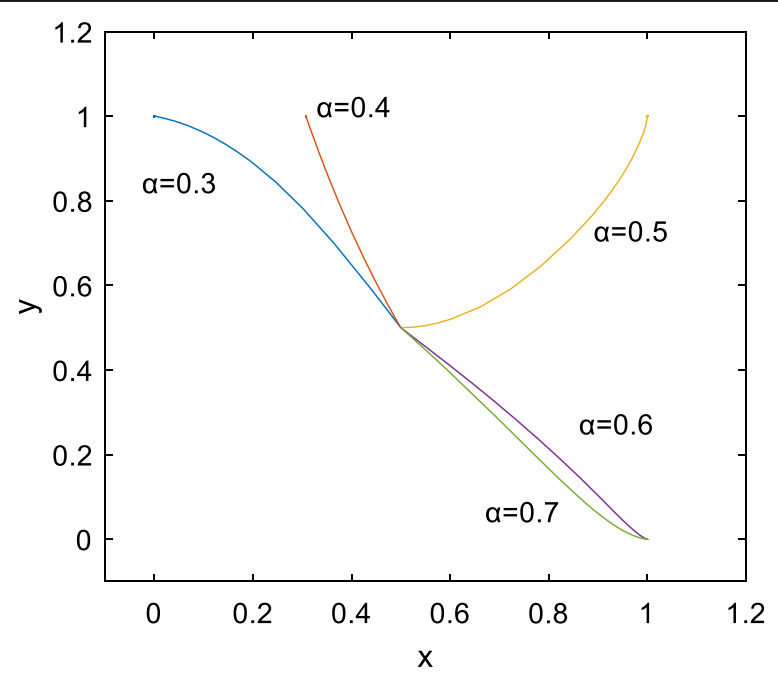

Fig. 9 Evolutionary game of the system with different distribution coefficients. Source: Authors' processing using Matlab 


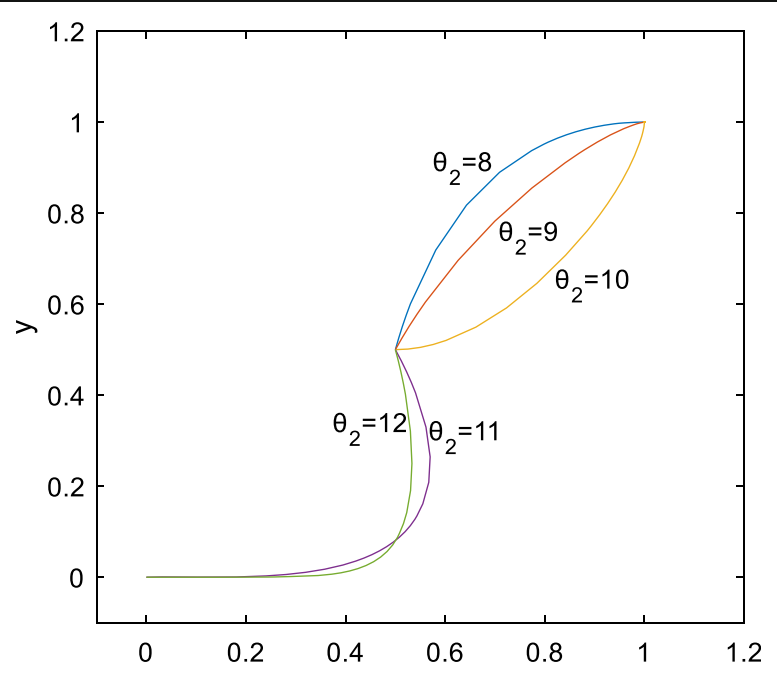

Fig. 10 Evolutionary game of the system with different costs. Source: Authors' processing using Matlab

Impact of penalty on the system evolution

Similarly, if $\theta_{1}=8, \theta_{2}=10, \Delta E_{1}=11, \Delta E_{2}=14, \Delta \pi=29, \alpha=0.5$ is set and $P=1,1.5,2$, $2.5,3$ is taken, Fig. 11 is obtained by using MATLAB 2016 to simulate processes of the evolutionary game of the PBE. With the increase of the penalty, the core enterprise and the cooperative enterprise change from adopting a non-collaboration strategy to adopting a collaboration strategy, and the stable strategy of system evolution changes from $(0,0)$ to $(1,1)$. As shown in Fig. 11, the increase of the penalty fee is beneficial for enterprises to choose a cooperative strategy.

\section{Suggestions on the development of the PBE}

This section translates the above theoretical findings into advice for the PBE building.

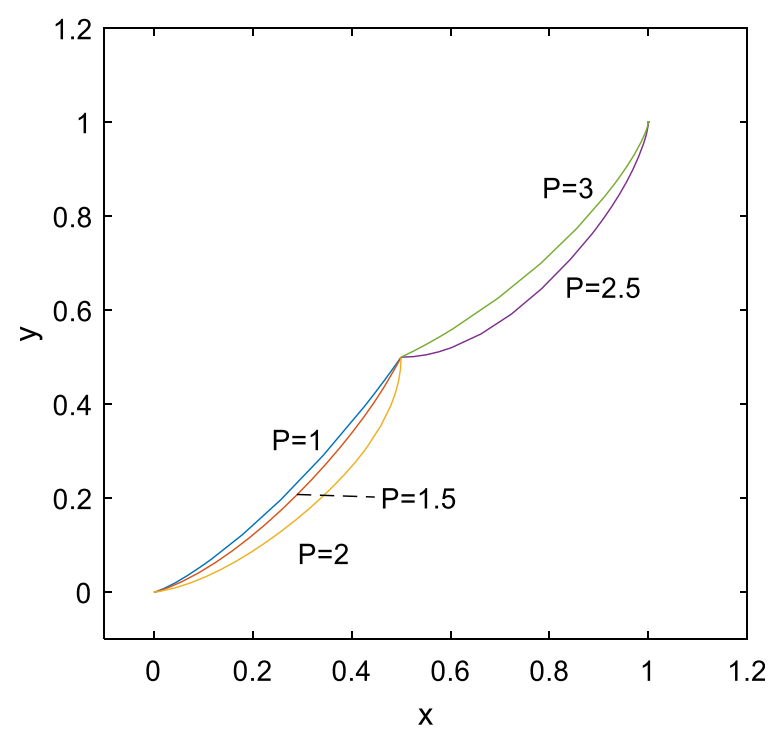

Fig. 11 Evolutionary game of the system with different penalties. Source: Authors' processing using Matlab 


\section{Construction of reasonable benefit-sharing mechanism}

The numerical simulations in 4.2.2 show that the benefit distribution coefficient will affect the result of the evolutionary game of the PBE. For the cooperative enterprises, the larger its distribution coefficient, the more willing they are to cooperate with the port enterprise, which is at the core of the ecosystem.

In the process of operation and management, port enterprises should not only ensure their interests but also should consider the interests of their cooperative enterprises. The members of the ecosystems pursue the maximisation of their interests, and the unfair distribution of interests will lead to the disorder and even disintegration of the systems.

All enterprises create values for the PBE. Only by creating value, one can attract participants to the ecosystem, and only these values can keep participants. In the process of collaborative development, the PBE realises value sharing and needs to construct a reasonable benefit-sharing mechanism to encourage enterprises to provide better and faster port, shipping, and logistics services, which is the core of ensuring the healthy development of the PBE.

\section{Construction of a reasonable punishment mechanism and reward mechanism}

The numerical simulations in 4.2.4 show that when other parameters are constant, the probability of cooperative enterprises choosing collaboration strategy gradually increases as the cost of implementing opportunism increases. By introducing a punishment mechanism, it is possible to change the cooperative enterprise from the noncollaboration to collaboration. Similarly, introducing a reward mechanism will be helpful for enterprises to choose the collaboration strategy instead of opportunism and improve the stability of the PBE.

\section{Construction of a trust mechanism}

The numerical simulations in 4.2.1 show that the larger the probability of the core enterprise choosing a collaboration strategy, the more the cooperative enterprise tends to choose a collaboration strategy. The initial strategy choice of either party will affect the strategy choice of the other party in the PBE. Trust is a lubricant and binder for the co-evolution of the PBE, and it is one of the several guarantee mechanisms for the stable operation of PBE. Enterprises should consciously increase their trust in each other, effectively reduce supervision costs and default risks, and promote the healthy and long-term development of the PBE. The establishment of a trust mechanism can be divided into pre-event, in-process and post-event.

The port enterprise must carefully select partners based on multiple criteria. Choosing a trusted logistics enterprise to cooperate is a means to reduce the risk of cooperation beforehand, which can also reduce the probability of opportunistic behaviour in cooperation. In the process of cooperation, the port enterprise should strengthen the supervision of the other logistics enterprises to ensure collaboration. If the cooperative enterprise adopts opportunism, the port enterprise can use the PBE information platform to inform other members of the opportunistic behaviour of the defaulting enterprise. All members can impose team sanctions on companies that engage in opportunistic behaviour or even drive them out of the PBE. 


\section{Attaching importance to the construction and improvement of platform of the PBE}

The numerical simulations in 4.2.3 show that the less the cooperative cost, the more the core and cooperative enterprise are inclined to adopt a collaborative strategy. The asymmetry of information between the game subjects and the instability of the trust relationship bring opportunities for the creation of speculative behaviour. Ports, as important nodes in the logistics and supply chain, naturally gather much information. The platform of the PBE can combine ports, cargo owners, shipping companies, logistics companies, service organisations and other members effectively to accelerate the deep integration of logistics, information and trade, which is conducive to the more convenient matching of logistics supply and demand and the PBE to provide more efficient port logistics services.

The construction of the information platform also contributes to promoting the sharing of information resources, prompting system members to form a good trust relationship, improving the convenience of cooperation, and reducing the cost of collaboration. The construction and improvement of the ecosystem information platform can circumvent the influence of the traditional system on system efficiency to a certain extent, and improve the fluency of information flow, capital flow, material flow and energy flow inside and outside the PBE.

\section{Conclusions}

This paper studies the evolution process of the PBE by using evolutionary game theory. The results show that the evolution results of the system are influenced by the initial state of the system, the cooperative cost, the distribution coefficient, and the penalty. In order to ensure the healthy development of the PBE, port enterprises, as the core of the ecosystem, should play a leading role and establish a reasonable benefit distribution mechanism, punishment mechanism and trust mechanism together with other members of the ecosystem. Meanwhile, they should attach great importance to the construction and improvement of the PBE platform. Apart from that, the research model of this paper is put forward based on some assumptions.

The actual cases have not been analysed in this paper, which need to be further studied in future research. Equally, incorporation of a port's characteristics (i.e. infrastructure, port governance, geographic location etc.) can be considered. Finally, the political environment, macro-economic environment, social environment and natural environment issues can be incorporated in an extension of the model for future research.

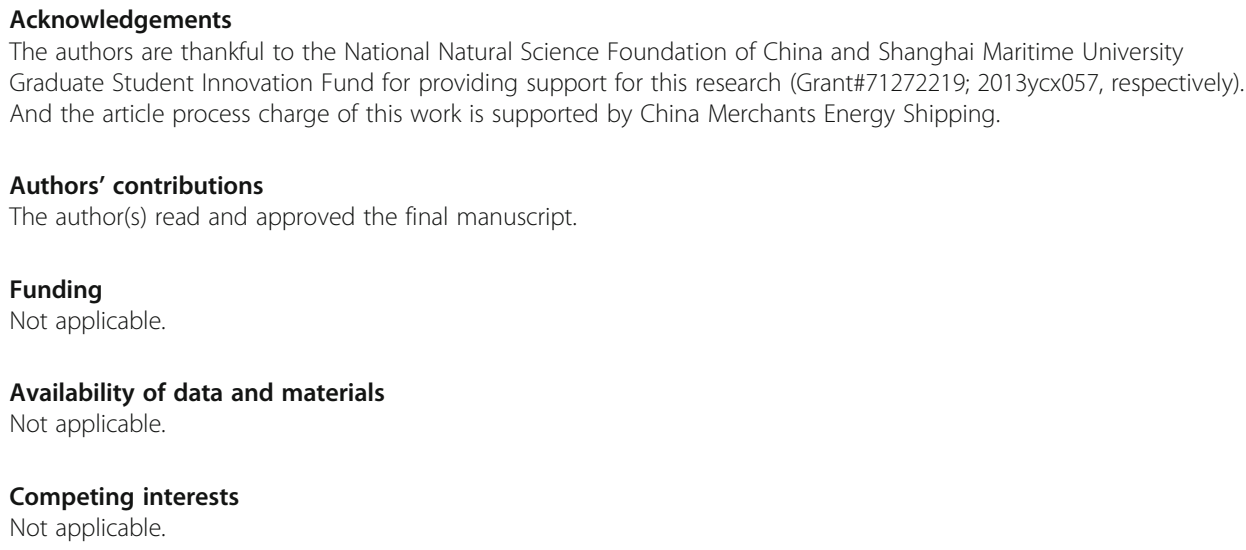




\section{Author details}

'Shanghai Maritime University, NO.1550 Haigang Ave, Shanghai 201306, China. ²University of Antwerp, Prinsstraat 13, 2000 Antwerpen, Belgium. ${ }^{3}$ Shanghai Dian Ji University, NO.1350 Ganlan Road, Shanghai 201306, China.

Received: 13 March 2020 Accepted: 1 September 2020

Published online: 19 October 2020

\section{References}

de Langen P W, Haezendonck E (2012) Ports as Clusters of Economic Activity. The Blackwell Companion to Maritime Economics. Wiley, New Jersey. p. 639-655.

de Langen PW, Visser EJ (2005) Collective action regimes in seaport clusters: the case of the lower Mississippi port cluster. J Transp Geogr 13(2):173-186

Fisher RA (1930) The genetic theory of natural selection. Clarendon Press, Oxford

Hidalgo-Gallego S, Nunez-Sanchez R, Coto-Millan P (2017) Game theory and port economics: a survey of recent research. J Econ Surv 31(3):854-877

lansiti M, Levien R (2004) The keystone advantage: what the new dynamics of business ecosystems mean for strategy, innovation, and sustainability. Harvard Business School Press, Boston

Ketchen DJ, Crook TR, Craighead CW (2014) From supply chains to supply ecosystems: implications for strategic sourcing research and practice. J Bus Logist 35(3):165-171

Kocsis A (2011) The role of port clusters in theory and practice. Reg Bus Stud 3(2):51-60

Kotowska I (2017) The issue of evaluation of a competitive position of a port Enterprise. A case study of bulk cargo-port Szczecin. Econ Problems Serv 17:47-63

Li C, Feng L, Han F et al (2015) Dynamic evolutionary game analysis of the E-business ecosystem. J Syst Sci 23(04):75-78

Li W, Liu W, Xu X et al (2017) The port service ecosystem research based on the Lotka-Volterra model. Polish Marit Res 24(s3): 86-94

Mangan J, Lalwani C, Fynes B (2008) Port-centric logistics. Int J Logistics Manage 19(1):29-41

McLaughlin H, Fearon C (2013) Understanding port and regional relationships: a new cooperation/competition matrix. Marit Policy Manag 40(3):278-294

Moore JF (1993) Predators and prey: the new ecology of competition. Harv Bus Rev 71(3):75-83

Moore JF (1996) The death of competition: leader and strategy in the age of business eco-systems. Harper Business Press, New York

Peltoniemi M. \& Vuori E. (2004). Business ecosystem as the new approach to complex adaptive business environments. Proceedings of Business Research Forum

Pettit S, Beresford A (2017) Port Management: Cases in Port Geography, Operations and Policy. Kogan Page, London. p. 1328.

Rong K, Lin Y, Shi Y et al (2013) Linking business ecosystem lifecycle with platform strategy: a triple view of technology, application and organization. Int J Technol Manag 62(1):75-94

Shao W (2013) Research on coordination mechanism of port service supply chain, Donghua University

Slack B (1985) Containerisation, inter-port competition, and port selection. Marit Policy Manag 12(4):293-303

Smith JM (1972) Game theory and the evolution of fighting. In: On Evolution, Edinburgh University Press, Edinburgh

Taylor PD, Jonker LB (1978) Evolutionary stable strategies and game dynamics. Math Biosci 40:145-156

Van de Voorde E, Vanelslander T (2014) Trends in the maritime logistics chain: vertical port co-operation: strategies and relationships. Port Business: Market Challenges and Management Actions, pp 121-140

Wang D, Zhang H (2014) Evolutionary game analysis on the coordination mechanism between regional ports. J Dalian Marit Univ 4:61-68

Wang X, Zhang Q (2013) Research on shipping cluster ecosystem-a case study of Dalian shipping service industry. Res Financ Issues 10:26-33

Wang Y, Meng W (2004) Evolutionary game analysis on co-competition mechanism of supply chain. J Ind Eng/Eng Manage 18(2):96-98

Williamson PG, de Meyer A (2012) Ecosystem advantage: how to successfully harness the power of partners. Calif Manag Rev 55(1):24-46

Yang M (ed) (2009) Management practice of general cargo ports. Shanghai People's Publishing House, Shanghai

Zhang H, Liu W (2017) Research on competitive advantages and strategies of port Enterprises in China. International Conference on Transformations \& Innovations in Management

Zhao N (2012) Port Strategic Coordination. Zhejiang University Press, Hangzhou.

Zhou X (2011) Research of port enterprises' cooperative strategy on emergencies. International conference on management and service science. IEEE, Wuhan

Zhou X, Ji J (2008) Evolutionary Game Analysis of Port Competition Cooperation Strategy. Navigation China 31(3):293-297

\section{Publisher's Note}

Springer Nature remains neutral with regard to jurisdictional claims in published maps and institutional affiliations. 